(昭和 39 年 9 月 10 日 受理)

触媒を含漫させを各種の繊維へのアクリロニトリル

のグラフト重合

$\begin{array}{lllll}\text { 京都大学高分子化学教室 } & \text { 桜 } & \text { 田 } & \text { 一 } & \text { 郎 } \\ \text { 甲南大学枕用化学教室 } & \text { 坂 } & \text { 口 } & \text { 康 } & \text { 義 }\end{array}$

\title{
GRAFT POLYMERIZATION OF ACRYLONITRILE ONTO VARIOUS FIBERS IMBIBING CATALYSTS
}

By Ichiro Sakurada* and Yasuyoshi Sakaguchi**

$\left(\begin{array}{l}\text { * Department of Polymer Chemistry, Kyoto University, Kyoto, Japan } \\ \text { Department of Applied Chemistry, Kōnan University, Higashinada- } \\ \text { ku, Kōbe, Japan }\end{array}\right.$

Various fibers imbibing solutions of several catalysts $\left(\mathrm{K}_{2} \mathrm{~S}_{2} \mathrm{O}_{8},\left(\mathrm{NH}_{4}\right)_{2} \mathrm{~S}_{2} \mathrm{O}_{3}, \mathrm{H}_{2} \mathrm{O}_{2}\right.$, AIBN and BPO) were heated with pure acrylonitrile in sealed tubes. The heating was carried out for $50 \mathrm{hrs}$ at $60^{\circ} \mathrm{C}$ or for $20 \mathrm{hrs}$ at $80^{\circ} \mathrm{C}$ in air. Solvents for catalyst to be imbibed were water, water-methanol mixtures, methanol and benzene-petroleum benzine mixtures. Concentrations of the catalysts were $0.3 \sim 2 \%$.

The grafting onto cellulose fibers proceeded smoothly in the presence of persulphates, but with difficulty in the presence of $\mathrm{H}_{2} \mathrm{O}_{2}, \mathrm{AIBN}$ and BPO. The efficiency of grafting onto viscose rayon was greater than that onto cotton. The grafting onto unheat-and heat-treated (at $200^{\circ} \mathrm{C}$ ) polyvinyl alcohol fibers proceeded easily when the catalyst was $\left(\mathrm{NH}_{4}\right)_{2} \mathrm{~S}_{2} \mathrm{O}_{8}$ or $\mathrm{H}_{2} \mathrm{O}_{2}$, but with difficulty when the catalyst was AIBN or BPO. The grafting onto nylon fibers proceeded to a considerable extent only in the case of $\left(\mathrm{NH}_{4}\right)_{2} \mathrm{~S}_{2} \mathrm{O}_{8}$ catalyst.

In contrast to the above mentioned fibers the grafting onto polyvinyl chloride fibers took place more smoothly in the presence of AIBN and BPO than in the presence of $\left(\mathrm{NH}_{4}\right)_{2} \mathrm{~S}_{2} \mathrm{O}_{8}$. The grafting of acrylonitrile onto polyester fibers was difficult throughout the experiments.

Instead of pure acrylonitrile an acrylonitrile-dimethyl formamide mixture ( $1: 1$ by volume) or $20 \%$ aqueous solution of acrylonitrile was used for the grafting, but the degree of grafting was always lower than that obtained with pure acrylonitrile. The grafting onto dried fibers imbibing catalysts was also difficult.

Generally the behaviors of grafting of acrylonitrile lay between those of styrene and vinyl acetate, and were rather near to those of vinyl acetate.

(Received September 10, 1964)

\section{1. 緒言}

著者らは既報においてい，セルロース，ポリビニアル コール (PVA), ナイロン, ポリ塩化ビニル (PVC) お よびポリエステル繊維にラジカル重合の一般的な開始郕 を含浸させこれをスチレン（St）また酢酸ビニル（V Ac）と加熱してグラフト重合物を製造する方法について 検討した。その結果，StはVAcに比ぺて一般にグラフ 卜重合を起こしやすいこと，七ルロース，PVA，ナイロ ン織維はPVC およびポリエステル瀻維に比べて一般に グラフト重合を起こしやすいこと，触媒溶液とモノマー
の繊維内部への浸入などの点に留意すれば，大部分の縄 維一モノマー系に特いてかなりのグラフト率が得られる ことなどを認めた。本街に扰いては，既報と同様の力法 により前述の諸㵶維へアクリロニトリル(AN)をグラフ 卜重合させた結果について述べる。

各種の高分子へのANのグラフト重合に関しては従来 多数の研究が行なわれている。たとえば桜田ら㤝放射線 照射法によるPVA 皮膜へのANのグラフト重合を検討 し，系に水などが共存するときはグラフト重合がかなり 起こることを認めている2。。しいながら大部分の報告 に淤いては，紫外線および放射線を用いる方法，ポリマ 
一をオソン酸化などによってあらかじめ化学的に改質す る方法，七リウム塩を用いる方法が採用されており，緎 維に過硫酸塩やアゾービスイソブチロニトリル (AIBN) などを含浸させて AN と接触させるグラフト法について

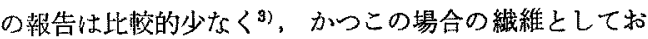
もにセルロース系と羊毛が用いられている。ANをSt心 よび VAc と此较すると, 単独重合の成長速度定数は St に近く，普通の共重合反応性は一般に両者の中間にあ り，溶媒連鎖移動定数は一般にVAc に近い。また PSt および PVAc は対応モノマーに溶けるのに, PAN は AN に溶けない点が特的である。

\section{2. 実験 方 法}

AN は市股品を蒸留して用いた。原料織維, 触媒, 瀻 稚への触媒の含浸法，モノマーとの加熱法，重量增加率，

Table 1. Graft polymerization of acrylonitrile in bulk onto viscose rayon fibers imbibing solutions of catalysts.

Dipping in catalyst solutions : $20 \mathrm{~min}$ (a. $20 \mathrm{hr}$ ) at $20^{\circ} \mathrm{C}$; imbibing solution: $1 \mathrm{~g} / \mathrm{g}-$ fiber ; monomer : $1.8 \mathrm{~g} / \mathrm{g}$-fiber ; polymerization : $50 \mathrm{hr}$ at $60^{\circ} \mathrm{C}$ (b. $20 \mathrm{hr}$ at $60^{\circ} \mathrm{C}$, c. 20 hr at $80^{\circ} \mathrm{C}$ ) uuder air.

\begin{tabular}{|c|c|c|c|c|c|}
\hline \multicolumn{2}{|c|}{$\begin{array}{l}\text { Catalyst in } \\
\text { imbib. soln., } \\
\%\end{array}$} & \multicolumn{2}{|c|}{$\begin{array}{c:c}\text { Solvent } & \text { in } \\
\text { imbib. } & \text { Weight } \\
\text { soln. } & \text { increase } \\
\text { vol } \% & \% \\
\end{array}$} & $\begin{array}{c}\text { Degree } \\
\text { of } \\
\text { grafting } \\
\%\end{array}$ & $\begin{array}{l}\text { Graft } \\
\text { efficien- } \\
\text { cy } \% \\
\%\end{array}$ \\
\hline $\mathrm{K}_{2} \mathrm{~S}_{2} \mathrm{O}_{8}$ & 0.3 & W 100 & 0 & - & - \\
\hline & 2 & $"$ & 171 & 146 & 85 \\
\hline \multicolumn{2}{|c|}{ b) $\left(\mathrm{NH}_{4}\right)_{2} \mathrm{~S}_{2} \mathrm{O}_{8}$} & W 100 & 178 & 149 & 84 \\
\hline a)b) & 1 & " & 164 & 138 & 84 \\
\hline \multirow[t]{2}{*}{ c) } & $" \prime$ & $" \prime$ & 157 & 144 & 92 \\
\hline & $" \prime$ & $\mathrm{W} 20-\mathrm{M} 80$ & 161 & 100 & 62 \\
\hline a) & " & " & 156 & 65 & 42 \\
\hline c) & $" t$ & " & 191 & 112 & 59 \\
\hline \multirow[t]{2}{*}{$\mathrm{H}_{2} \mathrm{O}_{2}$} & 0.3 & W 100 & 0 & - & - \\
\hline & 1 & " & 0 & - & - \\
\hline \multirow[t]{4}{*}{ a) } & $"$ & $"$ & 0 & - & - \\
\hline & " & $\mathrm{W} 40-\mathrm{M} 60$ & 3 & - & - \\
\hline & $"$ & W20-M80 & 3 & - & - \\
\hline & " & W 3-M97 & 5 & - & - \\
\hline a) & $"$ & $"$ & 2 & - & - \\
\hline a) $\operatorname{AIBN}$ & 1 & W20-M80 & 167 & 25 & 15 \\
\hline \multirow[t]{2}{*}{ a)c) } & $"$ & $"$ & 165 & 31 & 19 \\
\hline & $" \prime$ & M 100 & 2 & - & - \\
\hline a) & " & $"$ & 140 & 7 & 5 \\
\hline \multicolumn{2}{|c|}{ BPO 1} & M 100 & 0 & - & - \\
\hline
\end{tabular}

d: W. water, M. methanol
ダラフト率, ダラフト効率の求め方などは既報と同しで あるので，詳細は略す。重合後の ANホモボリマーの抽 出には一般にジィチルホルムフミド (DMFA) を用いた が，PVC 纖維だけはこの溶媒に溶けるので，程化雪鉻 の $60 \%$ 水溶液を用いた。

\section{3. セルロース繊維ヘのグラフト重合}

\section{$3 \cdot 1$ ビスコースレーヨンと純アクリロニトリルと の加熱}

まず普通ビスコースレーヨンに各種の触媒溶液を含㵊 させ、これを純 AN とともに封管中で加熱した。この結 果は第1表に示すと扣りである。

過硫酸カリ(KPS) または過硫酸フンモニウム(APS) の水溶液を含浸させた維維はきわめて円滑にグラフト熏 合を起こし，添加したANのほぼ全部が重合した条件に おいて 85\% 程度のグラフト効率が得られた。 APS 触 媒の場合, 溶媒として水の代りに水一メタノール混合液 を用いるとグラフト率が低下する。 $\mathrm{H}_{2} \mathrm{O}_{2}$ 触媒のとき性 重量增加率とグラフト率がともに低い。AIBN 触媒の場 合，溶媒としてィタノールを用いるとごく低いグラフト 率しか得られないが，含水メタノールを用いるとグラフ 卜重合がやや進む。過酸化ベンソイル（BPO）触媒のと きは重量增加率がごく低い。このような傎向は既報の女 ルロースーSt およびセルロース-VAc 系の場合に似てい るが，一般に AN はこれらの両モノマーの中間のグラフ

Table 2. Graft polymerization of acrylonitrile in bulk onto cotton fabrics imbibing solutions of catalyst.

Common experimental conditions are the same as in Table 1.

\begin{tabular}{|c|c|c|c|c|c|c|c|}
\hline \multicolumn{3}{|c|}{$\begin{array}{l}\text { Catalyst in } \\
\text { imbib. soln., } \\
\%\end{array}$} & $\begin{array}{l}\text { Solvent } \\
\text { in imbib. } \\
\text { soln. } \\
\text { vol } \%\end{array}$ & $\begin{array}{c}\text { Weight } \\
\text { increase } \\
\%\end{array}$ & $\begin{array}{c}\text { Degree } \\
\text { of } \\
\text { grafting } \\
\%\end{array}$ & $\begin{array}{r}\mathrm{Gr} \\
\mathrm{effi} \\
\mathrm{g} \text { cy }\end{array}$ & $\begin{array}{l}\text { traft } \\
\text { ficien- } \\
\% \\
\end{array}$ \\
\hline \multicolumn{3}{|c|}{ b) $\left(\mathrm{NH}_{4}\right)_{2} \mathrm{~S}_{2} \mathrm{O}_{8} 1$} & W 100 & 157 & 106 & 1 & 65 \\
\hline a)b) & & $" \prime$ & " & 158 & 66 & & 42 \\
\hline \multirow[t]{2}{*}{ c) } & & $" \prime$ & $"$ & 159 & 105 & & 66 \\
\hline & & $" \prime$ & W20-M80 & 161 & 31 & & 19 \\
\hline a) & & $" \prime$ & " & 163 & 19 & & 12 \\
\hline \multirow[t]{2}{*}{ c) } & & $\prime \prime$ & $"$ & 176 & 46 & & 26 \\
\hline & $\mathrm{H}_{2} \mathrm{O}_{2}$ & 1 & W 100 & 0 & - & & - \\
\hline \multirow[t]{2}{*}{ a) } & & $" \prime$ & " & 0 & - & & - \\
\hline & & $"$ & W 3-M97 & 0 & - & & - \\
\hline a) & AIBN & 1 & W20-M80 & 165 & 9 & & 6 \\
\hline \multirow[t]{2}{*}{ a)c) } & & $"$ & $" 1$ & 153 & 6 & & 4 \\
\hline & & $"$ & M 100 & 154 & 11 & & 7 \\
\hline a) & & $"$ & " & 138 & 7 & & 5 \\
\hline
\end{tabular}


ト挙動を示している。

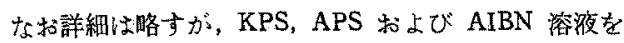
100\% 含漫させて後溶媒を蒸発させた瀻維を，純 AN と $60^{\circ} \mathrm{C}$ て 50 時間帛たは $80^{\circ} \mathrm{C} て ゙ 20$ 時間加熱したところ， いずれの場合も $10 \%$ 程度以下の重量增加率しか得られ なかった。この点はセルャースーVAc 采に似ている。

\section{2 綿布と純了クリロニトリルとの加熱}

次に各種の触葉溶液を含漫させた綿布を純 AN ととむ に加熱した。この結果は第2 表に示すとおりであり，A PS 念漫させた場合は $100 \%$ 以上のグラフト辛が得ら れた。重合諸条件の影望はレーヨンの場合と同様であ る。既報の St 招よび VAc の場合 と同様に，非晶化度の高いレーヨン のほうが木綿よりもグラフト重合が 起こりやすい。

\section{3 レーヨンおよび綿布とアク リロニトリル容液との加熱}

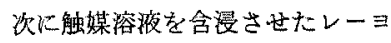
ソおよび綿有を，AN とこのポリマ 一の溶媒である DMFA との混合液 と加熱した。この結果は第 3 表に示 すと和りであり，純 $\mathrm{AN} と$ 加熱した 場合に比べると，重量增加率とグラ フト萃の両者が明らかに低い。また 第 4 表に示与上う火，AN の水溶液 と加熱したときの重量增加率とグラ フト率は第 3 表の結果よりるさらに 低い。

\section{4. ポリビニルアルコール}

\section{織維へのグラフト重合}

4.1 未熱処理䋡維へのグラフト

重合

紡系, 洗浄, 乾燥後の末熱処理 $\mathrm{P}$ VA 織維に触媒溶液を含漫させ，こ れを純 ANと加熱した。この㵶維は 水中で著しく収縮するので, 触媒溶 液としては含水率の低い当のを用い

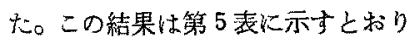
であり, APS 扎よび $\mathrm{H}_{2} \mathrm{O}_{2}$ の含水 メタノール溶液を含浸させた纎維は かなり高いダラフト率を示した。セ ルロースーAN 系では $\mathrm{H}_{2} \mathrm{O}_{2}$ 触媒の 場合にはグラフト重合が起こりにく かった。 St- $\mathrm{H}_{2} \mathrm{O}_{2}$ 打よび VAc- $\mathrm{H}_{2} \mathrm{O}_{2}$ 系に执いて， PVA 䋘維の活らが
セルロース瀻維よりもグラフト重合しやすい㑯向が認め られている。 $\mathrm{H}_{2} \mathrm{O}_{2}$ 触媒の場合も, 純人タノールを溶媒 に用いるとグラフト率が明らかに低下している。セル口 ース-AN, PVA-St, PVA-VAc 系之同梾に, AIBN お よび BPO 触媒を用いたのでは高いグラフト率は得られ ない。

次に触媒含浸縕維を AN-DMFA 湿合液と加熱した。 この結果は第 6 表に示すとお゙りであり，セルロースの場 合と同䇐にダラフト率は一般に低い。な和触媒含浸織維 を $\mathrm{AN} の 20 \%$ 水溶液と加熱すると，瀻維加者しく膠着 した。得られたグラフト率は最高 $10 \%$ 程度であった。
Table 3. Graft polymerization of acrylonitrile in dimethylformamide (AN : DMFA =1:1 by volume) onto cellulose fibers imbibing. solutions of catalysts.

Dipping in catalyst solution : $20 \mathrm{~min}$ at $20^{\circ} \mathrm{C}$; imbibing solution : $1 \mathrm{~g} / \mathrm{g}$-fiber, added monomer $: 1.8 \mathrm{~g} / \mathrm{g}$-fiber ; polymerization : $50 \mathrm{hr}$ at $60^{\circ} \mathrm{C}\left(* 20 \mathrm{hr}\right.$ at $\left.80^{\circ} \mathrm{C}\right)$ under air.

\begin{tabular}{|c|c|c|c|c|c|c|}
\hline Fiber & $\begin{array}{c}\text { Catalyst is } \\
\text { imbib. solr } \\
\%\end{array}$ & & $\begin{array}{c}\text { Solvent in } \\
\text { imbib. soln. } \\
\text { vol } \%\end{array}$ & $\begin{array}{c}\text { Weight } \\
\text { increase } \\
\%\end{array}$ & $\left|\begin{array}{c}\text { Degree of } \\
\text { grafting } \\
\%\end{array}\right|$ & $\begin{array}{c}\text { Graft } \\
\text { efficiency } \\
\%\end{array}$ \\
\hline \multirow[t]{2}{*}{ rayon } & $\left(\mathrm{NH}_{4}\right)_{2} \mathrm{~S}_{2} \mathrm{O}_{8}$ & 1 & W 100 & 95 & 28 & 25 \\
\hline & $"$ & & W 20-M 80 & 99 & 45 & 45 \\
\hline \multirow[t]{4}{*}{$*$} & " & & $" \prime$ & 90 & 23 & 26 \\
\hline & $\mathrm{H}_{2} \mathrm{O}_{2}$ & 1 & W 100 & 13 & 13 & 100 \\
\hline & $" \prime$ & & W 15-M 85 & 15 & 13 & 87 \\
\hline & AIBN & 1 & M 100 & 7 & - & - \\
\hline \multirow[t]{2}{*}{ cotton } & $\left(\mathrm{NH}_{4}\right)_{2} \mathrm{~S}_{2} \mathrm{O}_{8}$ & 1 & W 100 & 105 & 13 & 12 \\
\hline & " & & W $20-\mathrm{M} 80$ & 92 & 15 & 16 \\
\hline \multirow[t]{4}{*}{$*$} & $"$ & & " & 34 & 8 & 24 \\
\hline & $\mathrm{H}_{2} \mathrm{O}_{2}$ & 1 & W 100 & 20 & 7 & 35 \\
\hline & $" \prime$ & & W 15-M 85 & 20 & 7 & 35 \\
\hline & AIBN & 1 & M 100 & 46 & 8 & 18 \\
\hline
\end{tabular}

Table 4. Graft polymerization of acrylonitrile in $20 \%$ aqueous solution onto cellulose fibers imbibing solutions of catalysts. Common experimental conditions are the same as in Table 3.

\begin{tabular}{|c|c|c|c|c|c|c|}
\hline Fiber & $\begin{array}{l}\text { Catalyst in } \\
\text { imbib. soln } \\
\%\end{array}$ & & $\begin{array}{l}\text { Catalyst in } \\
\text { imbib, soln. } \\
\text { vol } \%\end{array}$ & $\begin{array}{c}\text { Weight } \\
\text { increase } \\
\%\end{array}$ & $\begin{array}{c}\text { Degree of } \\
\text { grafting } \\
\%\end{array}$ & $\begin{array}{c}\text { Graft } \\
\text { efficiency } \\
\%\end{array}$ \\
\hline \multirow{3}{*}{$\begin{array}{l}\quad \text { rayon } \\
* \quad\end{array}$} & $\left(\mathrm{NH}_{4}\right)_{2} \mathrm{~S}_{2} \mathrm{O}_{8}$ & 1 & W 100 & 79 & 22 & 28 \\
\hline & "I & & $" 1$ & 60 & 16 & 27 \\
\hline & "l & & W 20-M 80 & 43 & 14 & 33 \\
\hline \multirow[t]{2}{*}{$*$} & $" \prime$ & & $1 "$ & 57 & 15 & 26 \\
\hline & AIBN & 1 & M 100 & 23 & 7 & 30 \\
\hline \multirow[t]{2}{*}{ cotton } & $\left(\mathrm{NH}_{4}\right)_{2} \mathrm{~S}_{2} \mathrm{O}_{8}$ & 1 & W 100 & 71 & 10 & 12 \\
\hline & $" l$ & & W $20-M 80$ & 32 & 4 & 13 \\
\hline \multirow[t]{2}{*}{ * } & $" 1$ & & $" 1$ & 43 & 8 & 19 \\
\hline & AIBN & 1 & M 100 & 34 & 0 & 0 \\
\hline
\end{tabular}


Table 5. Graft polymerization of acrylonitrile in bulk onto unheat-treated polyvinyl alcohol fibers imbibing solutions of catalysts.

Common experimental conditions are the same as in Table 1.

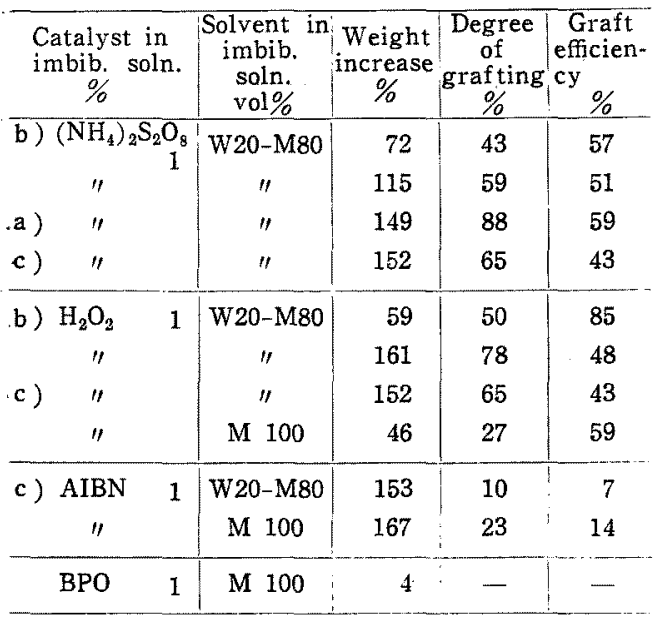

Table 6. Graft polymerization of acrylonitrile in dimethylformamide on to unheat-treated polyvinyl alcohol fibers imbibing solutions of catalysts.

Common experimental conditions are the same as in Table 3.

\begin{tabular}{|c|c|c|c|c|}
\hline $\begin{array}{c}\text { Catalyst in } \\
\text { imbib. soln. } \\
\%\end{array}$ & $\begin{array}{c}\text { Solvent in } \\
\text { imbib. } \\
\text { soln. } \\
\text { vol } \%\end{array}$ & $\begin{array}{c}\text { Weight } \\
\text { increase } \\
\%\end{array}$ & $\begin{array}{c}\text { Degree } \\
\text { of } \\
\text { grafting } \\
\%\end{array}$ & $\begin{array}{c}\text { Graft } \\
\text { efficien- } \\
\text { cy } \%\end{array}$ \\
\hline$\left(\mathrm{NH}_{4}\right)_{2} \mathrm{~S}_{2} \mathrm{O}_{3}$ & W20-M80 & 103 & 16 & 16 \\
\hline * $\quad$, & $" \prime$ & 164 & 13 & 8 \\
\hline $\mathrm{H}_{2} \mathrm{O}_{2}$ & "I & 47 & 14 & 30 \\
\hline AIBN & M 100 & 91 & 0 & 0 \\
\hline
\end{tabular}

\section{$4 \cdot 2$ 熱処理繊維へのタラフト重合}

次に $200^{\circ} \mathrm{C}$ で熱処理した緎維を用いて同溙な実験を行 活った。この縚果は一括して第 7 表に示した。APSの水 2-ハタノール8 混合液を含漫させた場合のグラフト萃 は，末熱処理織維よりもずっと低いが，水溶液を含浸さ せると，未熱処理㵶維よりももしろ离いグラフト率が得 られる。このような傾向は PVA-St 系に执いて死䜀め 战た。 $\mathrm{H}_{2} \mathrm{O}_{2}$ 触桇の場合は, 溶液中の水とメタノール の割合が5：5〜2：8のときにかなりのグラフト率が 得られ，含水率がこれ以上になると重量增加率が著しく 低下し，含水率がこれ以下になると重量增加率はほぼ不 変であるが，グラフト率加明らか低下している。PVA -St- $\mathrm{H}_{2} \mathrm{O}_{2}$ 系お゙よび PVA-VAc- $\mathrm{H}_{2} \mathrm{O}_{2}$ 系では含水率の 高い活うがグラフト重合がよく進しだ。繊維の膨潤とい
Table 7. Graft polymerization of acrylonitrile in bulk onto heat-treated (at $200^{\circ} \mathrm{C}$ ) polyvinyl alcohol fibers imbibing solutions of catalysts. Common experimental conditions are the same as in Table 3.

\begin{tabular}{|c|c|c|c|c|c|c|}
\hline \multicolumn{3}{|c|}{$\begin{array}{l}\text { Catalyst in } \\
\text { imbib. soln. } \\
\%\end{array}$} & $\begin{array}{l}\text { Solvent in } \\
\text { imbib. } \\
\text { soln. } \\
\text { vol\% }\end{array}$ & $\begin{array}{c}\text { Weight } \\
\text { increase } \\
\%\end{array}$ & $\begin{array}{c}\text { Degree } \\
\text { of } \\
\text { grafting } \\
\%\end{array}$ & $\begin{array}{c}\text { Graft } \\
\text { efficien- } \\
\text { cy } \\
\%\end{array}$ \\
\hline \multicolumn{3}{|c|}{$\left(\mathrm{NH}_{4}\right)_{2} \mathrm{~S}_{2} \mathrm{O}_{8} \quad I$} & W 100 & 159 & 90 & 60 \\
\hline \multirow[t]{3}{*}{ * } & $\prime \prime$ & & " & 150 & 63 & 42 \\
\hline & " & & W50-M50 & 159 & 52 & 33 \\
\hline & " & & W20-M80 & 142 & 6 & $\frac{1}{4}$ \\
\hline * & "I & & $" \prime$ & 115 & 25 & 22 \\
\hline \multicolumn{2}{|c|}{$\mathrm{H}_{2} \mathrm{O}_{2}$} & 1 & W 100 & 4 & - & -. \\
\hline \multirow[t]{2}{*}{$*$} & $"$ & & " & 8 & - & - \\
\hline & $\prime \prime$ & & W70-M30 & 0 & - & - \\
\hline \multirow[t]{2}{*}{$*$} & " & & $"$ & 25 & 19 & 76 \\
\hline & 13 & & W50-M50 & 138 & 45 & 33 \\
\hline \multirow[t]{2}{*}{$*$} & " & & $"$ & 109 & 42 & 39 \\
\hline & $" \prime$ & & W20-M80 & 133 & 34 & 26 \\
\hline \multirow[t]{2}{*}{$*$} & $" 1$ & & $" \prime$ & 139 & 46 & 33 \\
\hline & $\prime \prime$ & & M 100 & 129 & 12 & 10 \\
\hline \multicolumn{2}{|c|}{ AIBN } & 1 & W20-M80 & 156 & 10 & 6 \\
\hline * & $\prime \prime$ & & " & 70 & 21 & 30 \\
\hline
\end{tabular}

う観点からは，含水率の高い溶液のほうが有効なはずで ある。前述および後述のように， $\mathrm{H}_{2} \mathrm{O}_{2}$ の触媒效果は過 硫酸塩のそれと比べて,多くの瀻維一モノマー采に执いて かなり低いが, PVA-モノマー系ではそれほど低くはな い。PVA- $\mathrm{H}_{2} \mathrm{O}_{2}$ 柔にはこのよらな特徽が認められ，その 機構については今後の検討が必要である。なおAIBN触 媒の場合は，未熱処理㵶程の場合と同様に高いグラフト 率は得られなかった。

\section{5. ナイロン緎維ヘのグラフト重合}

次汇ナイロン瀻維に各種の独媒溶液を含漫後純 AN と 加熱した。この結果は第8表に示すとおりであり，APS のとくに水溶液を含浸させたときに，高い效率をもって グラフト重合が進んでいる。 $\mathrm{H}_{2} \mathrm{O}_{2}$ 触媒の場合，溶媒の スタノール含有量を高めると重量增加率は增大寸るが， いずれの場合にもグラフト率は低い。AIBN 触媒のとき は重量增加率は高いがダラフト率は低く，BPO 触蝶の ときは重量增加率も低い。これらの傾向は前述のセルロ ースーAN 系拉よびナイロン-VAc 系と活同じである。

また APS の $1 \%$ 水溶液を含浸させた瀻維を，AN の $20 \%$ 水溶液と $60^{\circ} \mathrm{C}$ で 50 時間または $80^{\circ} \mathrm{C}$ で 20 時間 加熱した。それぞれの場合に約 50\%の重量增加率々約 
Table 8. Graft polymerization of acrylonitrile in bulk onto nylon fibers imbibing solutions of catalysts.

Common experimeutal conditions are the same as in Table 3.

\begin{tabular}{|c|c|c|c|c|}
\hline $\begin{array}{c}\text { Catalyst in } \\
\text { imbib. soln. } \\
\%\end{array}$ & \multicolumn{2}{|c|}{\begin{tabular}{|c|c|} 
Solvent in & Weight \\
imbib. & increase \\
soln. & $\%$ \\
vol $\%$ & $\%$
\end{tabular}} & $\begin{array}{c}\text { Degree } \\
\text { of } \\
\text { grafting } \\
\%\end{array}$ & $\begin{array}{l}\text { Graft } \\
\text { efficien- } \\
\text { cy } \% \\
\end{array}$ \\
\hline$\left(\mathrm{NH}_{4}\right)_{2} \mathrm{~S}_{2} \mathrm{O}_{8}$ & W 100 & 155 & 117 & 76 \\
\hline$* \quad " \quad$ & " & 134 & 123 & 92 \\
\hline " & $\mathrm{W} 20-\mathrm{M} 80$ & 160 & 54 & 34 \\
\hline " & $"$ & 156 & 47 & 31 \\
\hline $\mathrm{H}_{2} \mathrm{O}_{2}$ & W 100 & 2 & - & - \\
\hline * $\quad " \prime$ & " & 0 & - & - \\
\hline$"$ & W50-M50 & 17 & - & - \\
\hline$"$ & $"$ & 0 & - & - \\
\hline " & W20-M80 & 85 & 8 & 9 \\
\hline$" 1$ & $"$ & 112 & 12 & 11 \\
\hline$"$ & W 3-M97 & 0 & - & - \\
\hline AIBN & W20-M80 & 160 & 0 & 0 \\
\hline * $\quad 11$ & " & 151 & 3 & 2 \\
\hline$" \prime$ & M 100 & 157 & 2 & 1 \\
\hline " & $"$ & 135 & 0 & 0 \\
\hline " & B50-PB50 & 155 & 3 & 0 \\
\hline$"$ & & 159 & 4 & 0 \\
\hline BPO & M 100 & 0 & - & - \\
\hline * $\quad \prime$ & $"$ & 23 & 0 & 0 \\
\hline
\end{tabular}

$35 \%$ のグラフト率をが得られた。さらに APS, $\mathrm{H}_{2} \mathrm{O}_{2}$ 和 よび AIBN の $1 \%$ 溶液を含浸後溶媒を蒸発させた紻維 を, 純 $\mathrm{AN}$ と $60^{\circ} \mathrm{C}$ で 50 時間加熱した。セルロースー AN 系およびナイロン-VAc 系と同样に，いずれの場合 る5\%以下の重量增加率しか得られなかった。

\section{6. ポリ塩化ビニル緎維へのグラフト重合}

AN はPVC 㵶維を著しく膨潤収縮させるので，触媒 溶液を含浸させた䌦維を AN-石油ベンシン混合液とと すに加熱した。この結果は一括して第 9 表に示した。 APS および $\mathrm{H}_{2} \mathrm{O}_{2}$ 触媒のときは数\%程度のグラフト率 しか得られないが, AIBN および BPO 触媒のときには かなりのグラフト率が得られた。 PVC-St 系に打いてる AIBN および BPO 触媒のほらが高いダラフト率が得ら れたが, APS および $\mathrm{H}_{2} \mathrm{O}_{2}$ 触媒の場合にもかなりのグ ラフト率が得られた。なお゙グフト率は重合温度 $80^{\circ} \mathrm{C}$ の汪うが $60^{\circ} \mathrm{C}$ よりる高い㑯向が認められる。

次江触媒溶液を含漫させた瀻維を AN の $20 \%$ 水溶液
Table 9. Graft polymerization of acrylonitrile in petroleum benzine (monomer : petroleum benzine $=2: 1$ by volume) onto polyvinyl chloride fibers imbibing solutions of catalysts.

Common experimental (conditions are the same as in Table 3.

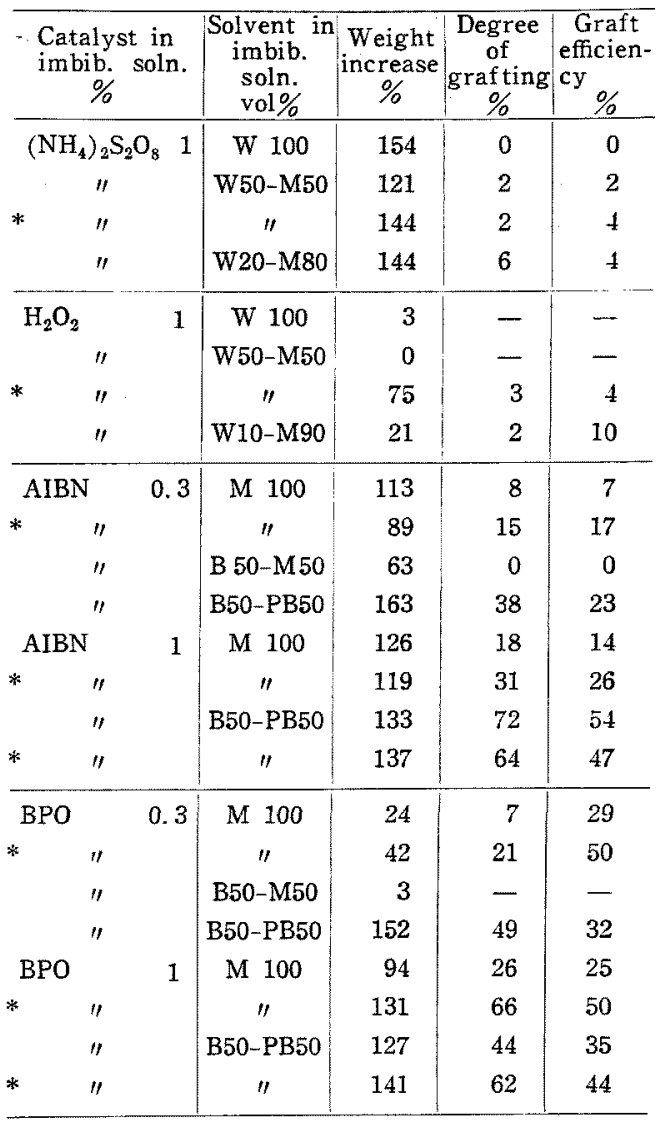

Table 10. Graft polymerization of acrylonitrile in $20 \%$ aqueous solution onto polyvinyl chloride fibers imbibing solutions of catalysts.

Common experimental conditions are the same as in Table 3.

\begin{tabular}{|c|c|c|c|c|c|c|}
\hline \multicolumn{3}{|c|}{$\begin{array}{c}\text { Catalyst in } \\
\text { imbib. soln. } \\
\%\end{array}$} & $\begin{array}{l}\text { Solvent in } \\
\text { imbib. } \\
\text { soln. } \\
\text { vol } \%\end{array}$ & $\begin{array}{c}\text { Weight } \\
\text { increase } \\
\%\end{array}$ & $\begin{array}{c}\text { Degree } \\
\text { of } \\
\text { grafting } \\
\%\end{array}$ & $\begin{array}{c}\text { Graft } \\
\text { efficien- } \\
\text { cy } \\
\%\end{array}$ \\
\hline \multirow{3}{*}{$*$} & AIBN & 1 & M 100 & 34 & 0 & 0 \\
\hline & $" 1$ & & $\prime \prime$ & 20 & 0 & 0 \\
\hline & $" 1$ & & B50-PB50 & 71 & 35 & 49 \\
\hline \multirow[t]{2}{*}{$*$} & $" \prime$ & & $" 1$ & 59 & 32 & 54 \\
\hline & $\mathrm{BPO}$ & 1 & M 100 & 38 & 24 & 63 \\
\hline * & $" \prime$ & & " & 39 & 33 & 85 \\
\hline
\end{tabular}


と加熱した。この結果は第 10 表に示すと招りであり， 第9表に比べて重䁂增加率とグラフト率が低い。これは 前过の緎維の場合と同じ傾向にある。

\section{7. テトロン繊維へのグラフト重合}

次にテトロン瀻維を KPS の $1 \%$ 溶液, APS 括よび $\mathrm{H}_{2} \mathrm{O}_{2}$ の $1 \%$ 水溶液, $1 \%$ 人ターール-水混合湢液, AIBN 扣上び BPO の $0.3 \sim 1 \%$ ×タノール溶液, 水一メタ, ール溶液, ベンゼンー石油ベンゼン溶液に $20^{\circ} \mathrm{C} て ゙ 20$ 分 または20時間浸せきし，含液率100\%に圧さくしてか ら, 純 ANを $60^{\circ} \mathrm{C} て ゙ 50$ 時間または $80^{\circ} \mathrm{C} て ゙ 20$ 時間 加熟した。結果の絴細は略すが，多くの場合に高い重量 增加率が得られたがク゚ラフト率は最高 $10 \%$ 程度に過 ぎかった。

また布に触媒溶液を含浸させ，溶媒を蒸発させてから 維 AN と加熱したが，いずれの場合にも10\% 以下のグ ラフト率しか得られなかった。このよらにテトロンーAN 乔の挙動はテトロン-VAc 采に似ている。

\section{8. 結訔}

以上のように, AN の各種の絒維へのグラフト重合の 挙動は一般に St のVAc の中間にあり, むしろ VAc に近い。このような結果はこれらのモ/マーの重合性の 観点から注理解することができ，適当条件に批いて は，モノマーの繊維に対する親和性の差異はグラフト挙 動に大きい影響を及ぼしていないと考点られる。この点 については他のモノマーを用いてさらに㛟討を行ないら つある。

\section{文献}

1) 桜田一郎, 坂口康義, 酒井保伊; 瀻学誌, 19, $217,221(1963), 20,392,398,402,454,458$ $463,548,555,613(1964)$, 同時揭載

2) 桜田一郎, 岡田紀夫, 久誈栄子; 放射線飞泀位体 2, $316(1959), 3,316$ (1960)

3) G. Landells et al ; J. Soc. Dyers Colourists, 67 338 (1951), F. B. Speakman et al ; J. Soc. Dyers Colourists, 70, 112 (1954), 77, 477 (1961), D. H. Haydel ; Textile Research J., 27 975 (1957), N. Geacintov et al.; Makromol. Chem., 36, 52 (1959); 松林察治; 傤学誌, 17, 498 (1961), その他 